\section{SEPTAL DEFECT AND PATENT DUCTUS ARTERIOSUSAFTER ASSISTED REPRODUCTIVE TECHNOLOGY}

\section{K.H. Lee}

Pediatrics, CHA Bubdang Medical Center, CHA University, Seongnam-si, Republic of Korea

Background \& aims: Lately several assisted reproductive technologies (ART) had been develped. while a lot of development, the structural defects and the relationship between congenital anomalies of infants conceived through ART are being actively studied. Among them, the relationship of development of cardiac defects between ART are rarely reported. This study investigated differences in neonatal septal heart defects and patent ductus arteriosus between ART and unassisted conception.

Methods: During 2005-2009, Among 9,836 newborns delivered, number of infants conceived by ART was 954 cases, 8,880 cases of unassisted conceived infants. In each group, ASD, VSD, PDA by echocardiogram before 3 months of age were diagnosed. And also chromosomal defect, other malformations were reviewed. Perinatal characteristics (gestational age, maternal age, birth weight, sex, multiple or single) were reviewed.

Results: The results of comparison ART group with unassisted conception group revealed gestational age $\left(35^{+6} \pm 2^{+5}\right.$ Week vs. $37^{+6} \pm 2^{+3}$ Weeks $)$ and birth weight $(2,470 \pm 620 \mathrm{~g}$ vs. $3,060 \pm 590 \mathrm{~g})$, multiple frequency rate $(68.2 \%$ vs. $6.4 \%)$. And also the incidence of ASD (0.5\% vs. $0.3 \%, P=0.197)$ and VSD $(0.5 \%$ vs. $0.3 \%, P=0.323)$ between groups did not differ, but incidence of PDA $(4.6 \%$ vs. $1.8 \%$, $\mathrm{P}<0.0001)$ of ART group was higher. Heart disease incidence was unrelated to multiple pregnancy $(\mathrm{P}=$ 0.743).

Conclusions: The incidence of ASD an VSD was not different between the ART group and unassisted conceived group. And the incidence of PDA was higher in ART group. However, considering the relating factors, ART was not related to the development of PDA

\section{EFFECT OF INDOMETHACINE INFUSION RATE FOR PATENT DUCTUS ARTERIOSUS ON CEREBRAL OXYGENATION IN PRETERM INFANTS}

\author{
E.M.W. Kooi', P.M.A. Lemmers ${ }^{2}$, E.A. Verhagen ${ }^{1}$, \\ P. Keating ${ }^{1}$, F. van Bel ${ }^{2}$, A.F. Bos ${ }^{1}$ \\ ${ }^{1}$ Neonatology, Beatrix Children's Hospital, \\ University Medical Center Groningen, Groningen, \\ ${ }^{2}$ Neonatology, Wilhelmina Children's Hospital, \\ University Medical Center Utrecht, \\ Utrecht, The Netherlands
}

Background: Indomethacine treatment for patent ductus arteriosus (PDA), might lead to vasoconstriction of cerebral blood vessels and under-perfusion of the brain. A lower infusion rate might prevent this. We aimed to determine the effect of two indomethacine infusion rates on fractional cerebral oxygen extraction (FTOE), which is indicative for cerebral blood flow.

Methods: In preterms with PDA, we compared the effect of indomethacine infusion $(0.2 \mathrm{mg} / \mathrm{kg})$ in 30 versus 60 minutes, on cerebral oxygenation. Patients in both groups were matched for GA, BW, PDA closure, and postnatal age. Near-infrared spectroscopy was used to measure regional cerebral oxygen saturation $\left(\mathrm{r}_{\mathrm{c}} \mathrm{SO}_{2}\right)$. Transcutaneous arterial oxygen saturation ( $\mathrm{tcSaO}_{2}$ ) was measured simultaneously. FTOE was calculated: $\left(\mathrm{tcSaO}_{2}-\right.$ $\left.\mathrm{r}_{\mathrm{c}} \mathrm{SO}_{2}\right) / \mathrm{tcSaO}_{2}$. We analyzed 6 episodes of 1 -h measurements: before, $1 \mathrm{~h}-4 \mathrm{~h}$, and 12 hours after treatment, using Mann-Whitney-U-test.

Results: Twenty infants (13 girls, median GA 27.0 weeks (range 25.3-28.7), BW 1007 gram (6151300), age 3.0 days (2-11)) were included, 10 in each group. No significant differences existed between the groups regarding GA, BW, age, effectiveness of indomethacine, need of surgery, and gender. The first hour after the start of treatment, we found an increase in FTOE of 0.04 in the 30 minutes-infusiongroup, compared to no change in FTOE in the 60 -minutes-infusion group $(p=.03)$. No significant differences were found at all other time-points.

Conclusion: Higher infusion rate of indomethacine for PDA seems to decrease cerebral blood flow the first hour, compared to lower infusion rate, possibly due to indomethacine induced vasoconstriction. The clinical relevance of this difference needs to be investigated. 